\title{
Let-7-mediated suppression of mucin 1 expression in the mouse uterus during embryo implantation
}

\author{
Wilasinee INYAWILERT'1), Tzu-Yen FU'1), Chun-Ting LIN ${ }^{1,2)}$ and Pin-Chi TANG ${ }^{1,3,4)}$ \\ ${ }^{1)}$ Department of Animal Science, National Chung Hsing University, Taichung 40227, Taiwan \\ 2) BioLASCO Taiwan Co., Taipei 115, Taiwan \\ 3) Agricultural Biotechnology Center, National Chung Hsing University, Taichung 40227, Taiwan \\ ${ }^{4)}$ Center for the Integrative and Evolutionary Galliformes Genomics, iEGG Center, National Chung Hsing University, \\ Taichung 40227, Taiwan
}

\begin{abstract}
Mucin 1 (Muc1) is an integral transmembrane mucin glycoprotein expressed on the apical surface of most epithelia. It is considered to be a barrier to the regulation of embryo implantation by inhibiting attachment of the embryo to the endometrium. Therefore, loss of Muc1 on the surface of uterine epithelial cells is necessary for embryo implantation. Studies have demonstrated that microRNAs (miRNAs) play a key role in enhancing embryo implantation in mammals. In this study, we investigated the regulatory role of two miRNAs (let-7a and let-7b) on the expression of Muc1 in mouse uteri during implantation. Western blotting indicated that Muc1 expression was highest on day 1 of pregnancy and constantly decreased thereafter until day 4. In contrast to Muc1 expression, increased expression of let-7a and let-7b was evident on day 4 of pregnancy as measured by real-time reverse transcription-polymerase chain reaction (real-time RT-PCR). We demonstrated direct binding of let-7a and let-7b to the 3'untranslated region of mucl. Furthermore, Muc1 expression was suppressed after transfection of mouse uterine epithelial cells isolated from day 1 of pregnancy with let-7a and let-7b. In summary, the present study provides evidence that Muc1 is a direct target of let-7a and let-7b. Additionally, the current study suggests that miRNAs are novel targets which can be used to facilitate a successful pregnancy and repair implantation failure.
\end{abstract}

Key words: Embryo implantation, miRNAs, Mucin1

(J. Reprod. Dev. 61: 138-144, 2015)

S ccessful embryo implantation depends on blastocyst quality and the timing of endometrial receptivity. However, unexplained embryo implantation failure sometimes occurs [1]. An interaction between the receptive endometrium and functional blastocysts is required for embryo implantation. Although a number of factors involved in this process have been examined, including endometrial morphology features, ovarian steroid hormones, adhesion molecules, pregnancy recognition signaling, cytokines, growth factors, microRNAs (miRNAs), uterine receptivity, and conceptus-uterus interactions [2-4], the detailed molecular mechanisms leading to successful implantation remain obscure [4].

Mucin 1 (Muc1) is a transmembrane glycoprotein belonging to the mucin family that is expressed in a variety of carcinomas and on the surface of epithelial cells in various organs, including the female reproductive tract, mammary gland, lung, kidney, stomach and pancreas [5-7]. In several species, Mucl presents on the surface of the uterine epithelia (UE) and acts as an anti-adhesive molecule to block embryo attachment to the endometrium [8-10]. The decreased Muc1 expression in terms of both mRNA and protein levels in the

Received: August 30, 2014

Accepted: December 16, 2014

Published online in J-STAGE: January 26, 2015

(C)2015 by the Society for Reproduction and Development

Correspondence: P-C Tang (e-mail: pctang@dragon.nchu.edu.tw)

This is an open-access article distributed under the terms of the Creative Commons Attribution Non-Commercial No Derivatives (by-nc-nd) License $<$ http://creativecommons.org/licenses/by-nc-nd/3.0/>. luminal and glandular UE at the time of implantation suggests that a reduction in Muc1 expression is essential during implantation [11-14]. After entering the uterus, the blastocysts go through the apposition, adhesion and invasion phases to establish implantation; at the same time, the endometrium becomes receptive for embryos [15]. Muc1 expression has been shown to be upregulated by progesterone [16] and may be more abundant in the receptive endometrium when both progesterone and estradiol levels are high [10]. Furthermore, the presence of blastocysts during the apposition phase may increase the expression of both UE Muc1 mRNA and protein levels. However, local Muc1 expression at the implantation site in humans has been shown to be diminished when blastocysts reach the adhesion phase and attach to the UE [10]. These studies demonstrated that the expression of UE Muc1 is regulated by the coordination of hormones and the embryo; thus, the anti-adhesive molecule Muc1 must be at least locally removed from the implantation site during the adhesion phase.

MiRNAs are 18-24 nucleotide non-protein-coding RNAs that participate in numerous biological processes, including development, cell proliferation and cell growth. MiRNAs regulate gene expression at the posttranscriptional level by binding to the coding region or the 3' untranslated region (3'UTR) of target mRNAs to cleave mRNAs or repress translation $[3,17,18]$. Many studies have indicated that miRNAs are involved in embryo implantation [3, 17-23]. The results from microarray and Northern blotting experiments demonstrated expression of the let-7 family in the mouse uterus during the periimplantation period, with let-7a, let- $7 b$, let $-7 c$, let $-7 d$, let $-7 g$, and let-7i upregulated at the implantation site [4]. Northern blotting 
analysis demonstrated that the expression of let-7a was higher on days 6-7 of pregnancy in rat uteri compared with on days 4-5 [18]. Furthermore, in situ hybridization data showed that let-7a expression was localized to the glandular and luminal uterine epithelia on day 4 of pregnancy, while a stronger signal was found in the decidua on day 6 . Additionally, let-7b expression was found to increase on day 4 of pregnancy (i.e., the receptive phase) compared with day 1 (i.e., the pre-receptive phase) in the mouse uterus [4, 24[REMOVED HYPERLINK FIELD]]. Our lab investigated the expression pattern of let-7b in mouse endometrial epithelial cells from days 1 to 4 of pregnancy and found that let-7b expression increased gradually from days 1 to 4 of the pre-implantation stage, with the highest expression on day 4 [3]. Therefore, the aim of the present study was to investigate the regulatory role of let-7 on the expression of Muc1 during implantation in mice.

\section{Materials and Methods}

\section{Animals}

Sexually mature female mice (CD-1, 8 weeks old) were purchased from BioLASCO Taiwan. The animals were maintained in an individually ventilated cage (IVC) system under lighting conditions of $14 \mathrm{~h}$ of light ( $0700-2100 \mathrm{~h}$ ) and $10 \mathrm{~h}$ of darkness. Food and water were provided ad libitum. The use of animals and the procedures for animal handling and treatments were approved by the Institutional Animal Use and Care Committee (IACUC) at National Chung Hsing University (no. 99-83). Female mice in the estrous stage were caged overnight with fertile males of the same strain to induce pregnancy. Mating was verified by the presence of a vaginal plug the following morning, which was designated as day 1 of pregnancy.

\section{Isolation of mouse endometrial epithelial cells}

The female mice were sacrificed in the afternoon on days 1 , 2, 3 and 4 of pregnancy. The endometrium isolation method was performed as described previously [25[REMOVED HYPERLINK FIELD]]. Briefly, the lumen of excised uterine horns was filled with 0.76\% EDTA (pH 7.4; Sigma, St Louis, MO, USA) in Dulbecco's phosphate-buffered saline (DPBS), and whole tissues were incubated at $37 \mathrm{C}$ in $5 \% \mathrm{CO}_{2}$ for $20 \mathrm{~min}$. The endometrial epithelium was scraped off from the inner wall of the uteri for protein extraction. For cell culture, the inner wall of the uteri were then incubated in collagenase type I $(1 \mathrm{mg} / \mathrm{ml})$ in DPBS at $37 \mathrm{C}$ in $5 \% \mathrm{CO}_{2}$ for another $20 \mathrm{~min}$. The endometrial epithelial cells were spun down for $30 \mathrm{sec}$, and the cell pellets were washed with DPBS three times and resuspended in Dulbecco's modified Eagle's medium (DMEM; Sigma) supplemented with $10 \%$ fetal bovine serum (FBS; Biological Industries, Kibbutz Beit-Haemek, Israel). All cells in this study were maintained in DMEM supplemented with $10 \% \mathrm{FBS}$ at $37 \mathrm{C}$ in a humidified $5 \% \mathrm{CO}_{2}$ incubator.

\section{Western blotting}

The mouse uterine epithelia harvested during days 1 to 4 of pregnancy were subjected to sodium dodecyl sulfate polyacrylamide gel electrophoresis (SDS-PAGE). The endometrial scrapings were lysed in the sample extraction buffer (RIPA lysis buffer; $150 \mathrm{mM} \mathrm{NaCl}$; 1\% Nonidet P-40; 50 mM Tris, $\mathrm{pH} 8.0 ; 0.5 \%$ sodium deoxycholate;
$0.1 \%$ sodium dodecyl sulfate; and 1:100 protease inhibitor). Equal amounts of total protein were denatured in electrophoresis sample buffer (10\% SDS; $0.5 \mathrm{M}$ Tris, $\mathrm{pH} 6.8 ; 20 \% \mathrm{v} / \mathrm{v}$ glycerol; and $0.2 \%$ $\mathrm{w} / \mathrm{v}$ bromophenol blue). After boiling at $95 \mathrm{C}$ for $5 \mathrm{~min}$, proteins $(95 \mu \mathrm{g})$ from each sample were analyzed on $6.5 \%$ polyacrylamide gel. Afterwards, the proteins were transferred onto nitrocellulose (NC) membranes in transfer buffer (25 mM Tris-HCl, pH 8.3; 192 $\mathrm{mM}$ glycine; and $10 \%$ methanol) at a constant $300 \mathrm{~V}$ for $1 \mathrm{~h}$. The $\mathrm{NC}$ membranes were blocked in 5\% skim milk in $20 \mathrm{mM}$ Tris- $\mathrm{HCl}$, $500 \mathrm{mM} \mathrm{NaCl}$ and $0.05 \%$ Tween 20 (TTBS) at room temperature for $2 \mathrm{~h}$. After a brief wash with TTBS, the membranes were probed with rabbit polyclonal anti-Muc1 antibody (1:800 dilution in TTBS containing 3\% skim milk; GTX15481, GeneTex, Irvine, CA, USA) or mouse anti-actin antibody (1:8000 dilution in TTBS containing 3\% skim milk; MAB1501, Chemicon, Merck Millipore, Billerica, MA, USA) at room temperature for $2 \mathrm{~h}$. After several thorough washes with TTBS, the NC membranes were incubated with HRPconjugated goat-anti-rabbit IgG antibody (1:5000 dilution in TTBS containing 3\% skim milk; KPL, Kirkegaard \& Perry Laboratories) or goat-anti-mouse antibody (1:15,000 dilution in TTBS containing $3 \%$ skim milk; Backer Man) at room temperature for $40 \mathrm{~min}$. After washing with TTBS, the NC membranes were visualized using a SuperSignal ${ }^{\circledR}$ West Femto kit (Thermo Scientific, Waltham, MA, USA) according to the manufacturer's instructions.

\section{Real-time reverse transcription polymerase chain reaction (RT-PCR)}

Total RNA from mouse endometrial epithelial cells collected from days $1-4$ of pregnancy were extracted individually using TRIzol ${ }^{\circledR}$ (Invitrogen by Life Technologies). The reverse transcription (RT) reaction was carried out according to manufacturer's suggestion using the ABI TaqMan MicroRNA assay protocol (Applied Biosystems by Life Technologies, Carlsbad, CA, USA). Briefly, 3 ng of each total RNA was used as a template in $20 \mu \mathrm{l}$ of RT reaction mixture containing let-7a, let-7b or snoRNA 412 (as an internal control) reverse primers (Applied Biosystems by Life Technologies), $50 \mathrm{U}$ MultiScribe $^{\mathrm{TM}}$ Reverse Transcriptase, $3.8 \mathrm{U}$ RNase inhibitor, 81 $\mathrm{mM} \mathrm{dNTP}$ and $1 \times$ reverse transcription buffer. The RT reaction was conducted as follows: the mixture was incubated at $16 \mathrm{C}$ for $30 \mathrm{~min}, 42 \mathrm{C}$ for $30 \mathrm{~min}$; and then $85 \mathrm{C}$ for $5 \mathrm{~min}$. The RT product was maintained at $4 \mathrm{C}$. A $1.33 \mu \mathrm{l}$ aliquot of RT products was used as a template for each $20 \mu \mathrm{l}$ polymerase chain reaction (PCR) mixture according to the manufacturer's instructions (Applied Biosystems by Life Technologies). Briefly, each real-time PCR reaction was performed using $1 \times$ TaqMan Universal Master Mix, No AmpErase UNG and $1 \times$ TaqMan microRNA assay (let-7a, let-7b or snoRNA 412 ) at $98 \mathrm{C}$ for $10 \mathrm{~min}$, followed by 40 cycles at $98 \mathrm{C}$ for $15 \mathrm{sec}$ and $60 \mathrm{C}$ for $1 \mathrm{~min}$. The reactions were performed on an StepOne machine (Applied Biosystems by Life Technologies). All data were calculated by the $\Delta \Delta \mathrm{Ct}$ method for relative quantification of gene expression as described previously $[3,25]$.

\section{Transfection}

The complete sequence of the muc1 3'UTR (National Center for Biotechnology Information reference sequence NM_013605.1) was amplified by PCR from mouse genomic DNA forward primer 
(5'-CGTCTAGAGAGCAAGTCACCCCACCCAC-3') and reverse primer (5'-CGTCTAGAGGCCATCTTTTATTCAGCTA-3'); both primers contained the addition of the recognition sequence for the $X b a \mathrm{I}$ restriction enzyme at the 5 'ends. Next, the amplified mucl 3' UTR (271 bp) was cloned into the pRL-SV40 vector (Promega, Madison, WI, USA) through the $X b a$ I site located immediately downstream of the luciferase gene. This constructed vector was designated as the pRL-Muc1 vector. A total of $1.5 \times 10^{4} \mathrm{~B} 16 \mathrm{~F} 10$ cells that express endogenous let-7a (data not shown) and let-7b [26[REMOVED HYPERLINK FIELD]] were seeded onto 24-well culture plates. Transfection was performed using the Lipofectamine 2000 reagent (Invitrogen by Life Technologies, Carlsbad, CA, USA) according to the manufacturer's instruction. Briefly, 200 ng of pRL-SV40 vector plus $40 \mathrm{ng}$ of pGL3 vector (a kind gift from Dr YL Shiue, Institute of Biomedical Sciences, National Sun Yat-Sen University, Kaohsiung, Taiwan), which served as an internal control, and the pRL-Muc1 vector with/without 100 pmol of let-7a inhibitor (let-7a antisense sequence, 2'-methlyloligonucleotides: 5'AACUAUACAACCUACUACCUCA'3; Applied Biosystems by Life Technologies) or let-7b inhibitor (let-7b antisense sequence, 2'-methlyl-oligonucleotides: 5' AACCACACAACCUACUACCUCA'3; IDT, Integrated DNA Technologies, Coralville, IA, USA) were diluted in Opti-MEM ${ }^{\circledR}$ I Reduced Serum Medium (Invitrogen by Life Technologies) without serum (or other medium without serum) and mixed gently. The Lipofectamine 2000 reagent was diluted with Opti-MEM ${ }^{\circledR}$ I Medium, mixed gently before use and incubated at room temperature for 5 $\mathrm{min}$. Then, the diluted Lipofectamine 2000 was combined with the diluted vectors and let-7a or let-7b inhibitors. After gentle mixing and incubation for $20 \mathrm{~min}$ at room temperature, the mixture was added to each well containing cells and medium. After $6 \mathrm{~h}$, the medium was replaced with fresh medium. Cells were harvested and lysed $30 \mathrm{~h}$ after transfection; then, the Dual Luciferase Reporter assay system (Promega) was applied to analyze the expression of luciferase in the transfected cells according to the manufacturer's instructions. Cells transfected with Lipofectamine 2000 reagent only without miRNA inhibitor served as the control [3].

\section{In vitro embryo adhesion assay}

Mouse uterine epithelial cells harvested in the afternoon from one mouse on day 1 of pregnancy were seeded onto 24-well culture plates and transfected with $100 \mathrm{pmol}$ of let-7a or let-7b precursor (Ambion Applied Biosystems, Austin, TX, USA) as described previously [25]. After $48 \mathrm{~h}$, the hatching mouse blastocysts ( 8 hatching blastocysts for each group in each of 4 replicate experiments for a total of 96 hatching blastocysts used in this experiment) collected from pregnant mice were transferred and cultured onto the monolayers of uterine epithelial cells for $24 \mathrm{~h}$. The cells transfected with Lipofectamine 2000 reagent only without the let-7a or let-7b precursor served as the control group. The embryos were scored as unattached if they moved from their original location when the plates were shaken and scored as attached if they did not move freely.

\section{Statistical analysis}

One of three statistical methods (Student's $t$-test, one-way ANOVA followed by LSD, and Chi square analysis) was applied to analyze the data according to the experimental design. These analyses were conducted with a statistical analysis system program (SAS version 9.1; SAS Institute, Cary, NC, USA) to determine significant differences among experimental groups in various experiments. $P$ values less than 0.05 were considered significantly different.

\section{Results}

Expression of the Muc1 protein in mouse endometrial epithelial cells during early pregnancy

Western blotting was performed to analyze Muc1 protein levels during pregnancy (days 1 to 4 ) using lysates of uterine endometrial cells. The results showed that Muc1 protein expression was highest on day 1 of pregnancy and constantly decreased until day 4. A significant difference was found between days 1 and 4 of pregnancy ( $<<0.05$; Fig. 1).

Expression of let-7a and let-7b in mouse endometrial epithelial cells during early pregnancy

The mouse uterine endometrial epithelia harvested on days 1 to 4 of pregnancy were examined for the expression of let-7a during early pregnancy using real-time RT-PCR. The results showed that the expression of let-7a gradually increased from day 1 to day 4 of pregnancy, reaching the highest level on day 4 (Fig. 2). This pattern is similar to the let-7b expression pattern demonstrated previously [26]. Additionally, the expressions of both let-7a and let- $7 b$ expression on day 4 of pregnancy were significantly higher than on days 1 and 2 (Fig. 2).

\section{Let-7a and let-7b directly target the 3'UTR of muc1}

Using online databases including MicroCosm Targets (http:// www.ebi.ac.uk/enright-srv/microcosm/cgi-bin/targets/v5/detail_view. pl?transcript_id=ENSMUST00000041142) and Diana miRGen (http:// www.diana.pcbi.upenn.edu/cgi-bin/miRGen/v3/Targets.cgi\#Results), we found that the seed regions of let-7a and let-7b matched sites in the 3'UTR of mucl (Fig. 3a). Therefore, a luciferase assay was applied to validate whether let-7a and let-7b bind directly to the 3'UTR of mucl. We constructed a reporter plasmid (pRL-Muc1) in which the 3'UTR of mucl was subcloned immediately downstream of the luciferase gene in the plasmid pRL-SV40. Transfection with the desired vectors or nucleotide sequences according to the experimental design was conducted in the $\mathrm{B} 16 \mathrm{~F} 10$ cell line. The results showed that the luciferase activities in the cells co-transfected with pRL-Muc1 and pRL-SV40 were significantly lower than in the cells transfected with pRL-SV40 alone (Figs. $3 \mathrm{~b}$ and 3c). Transfection of either let-7a or let-7b inhibitors with pRL-SV40 in B16F10 cells had no effect on the expression of luciferase activity, but the suppression of luciferase activity in cells transfected with pRL-Muc1 was significantly restored after transfection of either let-7a inhibitor or let-7b inhibitor (Figs. $3 \mathrm{~b}$ and $3 \mathrm{c})$. These results indicate that Muclis the target gene of let-7a and let-7b.

\section{Suppression of $M u c 1$ by overexpression of let-7a or let-7b}

In addition to the evidence from the luciferase assay, the negative regulation of Muc1 by let-7a and let-7b was further confirmed by immunoblotting. The uterine endometrial epithelia collected from 
(a)

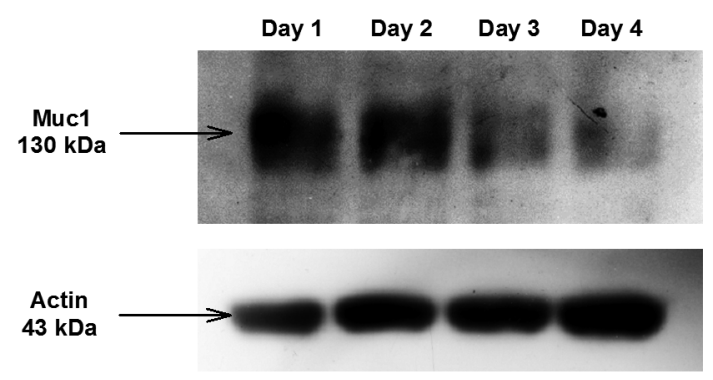

(b)

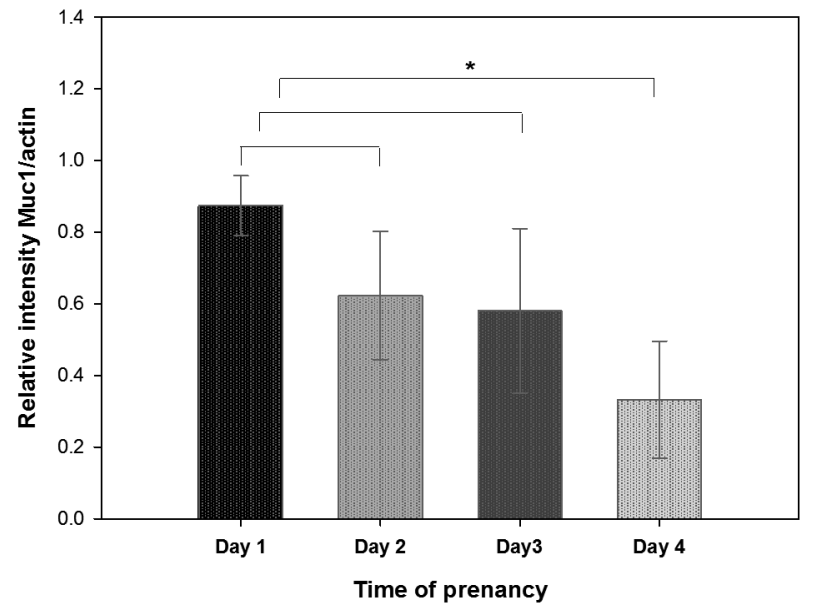

Fig. 1. Expression of Muc1 analyzed by Western blotting in endometrial epithelial cells collected from mice during early pregnancy. Mouse uterine epithelia harvested during days 1 to 4 of pregnancy (one mouse for each stage of days 1 to 4 for a total of 12 mice in three replicates) were subjected to the Western blotting assay. (a) The expression of Muc1 was detected with a molecular weight of $130 \mathrm{kDa}$. (b) The relative expression of MUC1 was normalized to $\beta$-actin and analyzed with the ImageJ software (version $1.44 \mathrm{p}$; National Institutes of Health, Bethesda, MD, USA). Asterisks indicate statistical significance $(\mathrm{P}<0.05)$ by Student's $t$-test. Data are expressed as the mean \pm SEM.

mice on day 1 of pregnancy were transfected with let-7a or let-7b precursors for $72 \mathrm{~h}$, and the expression of Mucl was analyzed by immunoblotting. Due to the limitations of primary cell culture, $50 \mu \mathrm{g}$ of total protein from each sample was applied in this assay. The expression of Muc1 was significantly downregulated in the endometrial epithelial cells transfected with the $l e t-7 a$ or let-7b precursors compared with the control group (Fig. 4). Taken together, the current data suggested that the suppression of Muc1 in the mouse uterine endometrial epithelia is mediated by let-7a and let- $7 b$.

\section{Reduction of embryo adhesion to the endometria by let-7a and let-7b}

Next, we investigated the effect of let-7a and let-7b on embryo adhesion. Mouse embryo adhesion assays were performed on mouse uterine epithelial cells collected from mice on day 1 of pregnancy. After transfection of let-7a or let-7b precursors for $48 \mathrm{~h}$, cells were cocultured with mouse hatching blastocysts for another $24 \mathrm{~h}$.

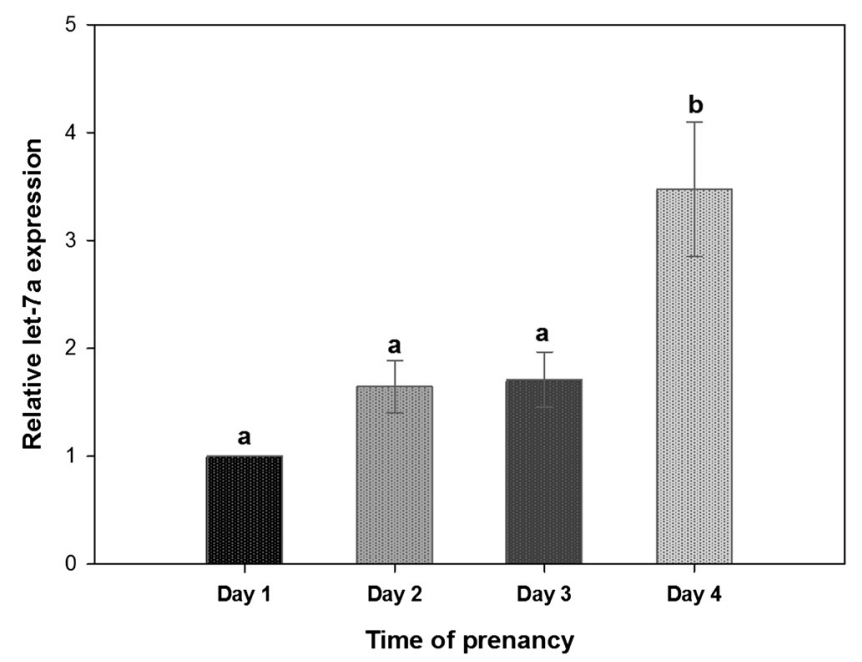

Fig. 2. Changes in let-7a expression in the mouse uterine epithelia during early pregnancy from days 1 to 4 by real-time RT-PCR analysis. Total RNA from mouse endometrial epithelial cells from days 1-4 of pregnancy (one mouse for each stage) was extracted to conduct real-time RT-PCR. Day 1 was designated as the day that a vaginal plug was found. Bars with different letters differ significantly (P $<0.05)$ by one-way ANOVA followed by the LSD test. Data are expressed as the mean \pm SEM from three replicates $(n=12$ mice).

Embryo attachment was evaluated by shaking the culture plates. The percentages of embryo adhesion were increased in the groups of blastocysts cocultured with epithelia transfected with let-7a and let- $7 \mathrm{~b}$ precursors compared with the control group (34\% and $47 \%$ vs. $19 \%$; $\mathrm{P}<0.01$; Table 1).

\section{Discussion}

The successful implantation process relies on cross talk between the embryo and uterine epithelia, which requires well-developed blastocysts and differentiated receptive uteri. The reduction of Muc1 on uterine luminal epithelial cells or in the confined region (i.e., the implantation site) before embryo attachment to the receptive uterus is important to guide the blastocyst to the precise area that is fittest for implantation [27-30,44]. The implantation window during which the endometrium becomes receptive for embryos is sustained for a confined period of time $[15,31]$. In mice, the uterus becomes receptive on day 4 of pregnancy or pseudopregnancy and continues to the refractory state on day 5 [32]. In the present study, the results showed that Muc1 expression was high on day 1 and constantly decreased until day 4 of pregnancy (Fig. 1). Therefore, our results are in agreement with previous reports indicating that Muc1 expression is downregulated in the uterine epithelia during the window of the receptive phase before blastocyst attachment [12].

It has been demonstrated that the decrease in Muc1 expression on the receptive endometrium is correlated with ovarian steroid hormones. Muc1 can be upregulated by estrogen and regulated by progesterone. The interaction between embryos and epithelia is facilitated under hormonal regulation [14]. Moreover, studies have implicated miRNAs as one of the regulatory factors involved 
(a)
Let $-7 a$
Let-7b
UGAGGUAGUAGGUUGU-AUAGUU
Muc1
UGAGGUAGUAGGUUGUGUGGUU
ACTCCCTCGTCTGGCGGTTTCGA

(b)

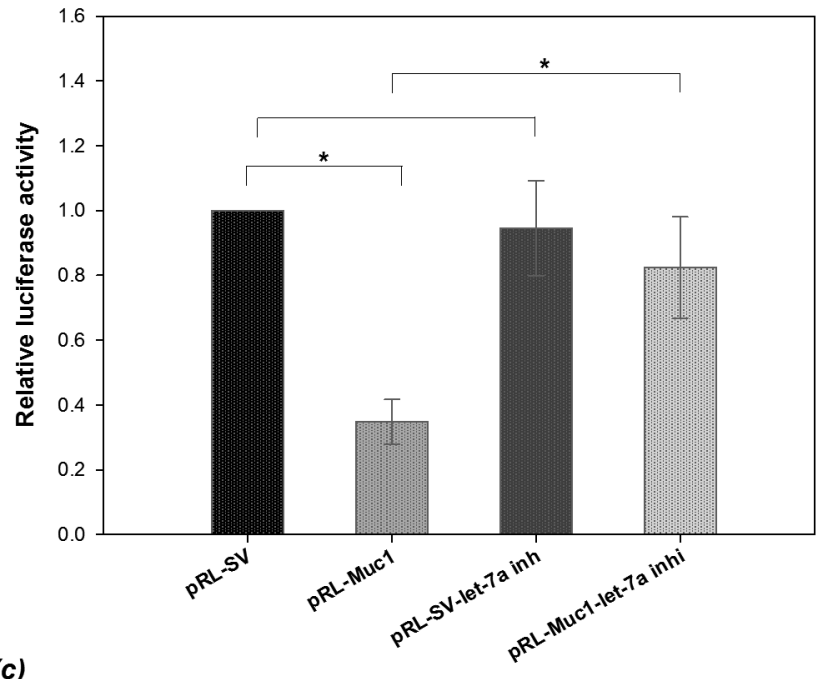

(c)

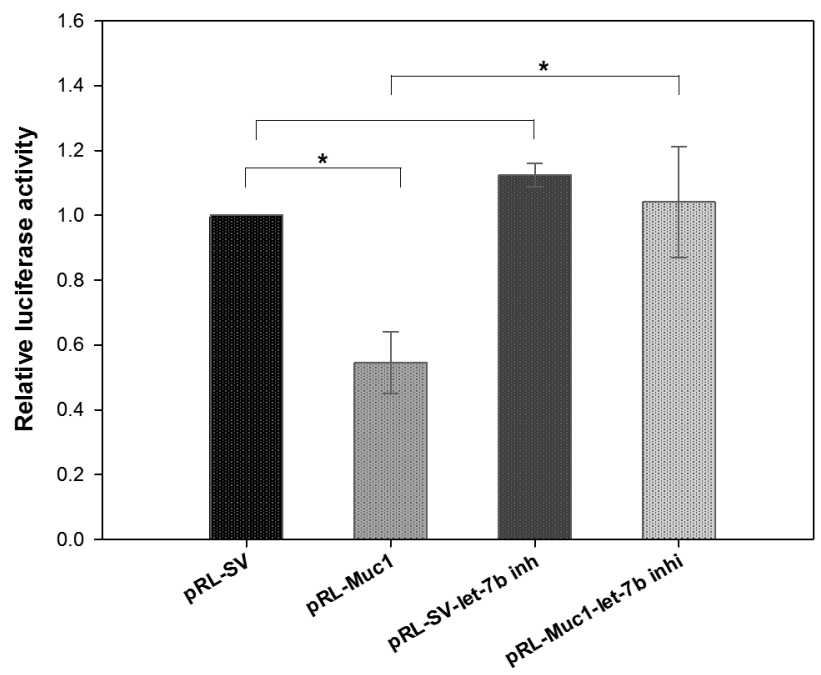

Fig. 3. Let-7a and let-7b target the 3'UTR of Muc1. (a) GAGGUAG (underlined) is the seed region of let-7a and let-7b and is almost complementary to the Mucl 3'UTR. Analyses of luciferase activities were conducted in B16F10 cells transfected with pRLMuc1 and a let-7a inhibitor (b), or with pRL-Muc1 and a let-7b inhibitor (c). pRL-SV, cells co-transfected with pRL-SV40 and pGL3 vectors; pRL-Muc1, cells co-transfected with both pRLMuc1 and pGL3 vectors; pRL-SV-let-7a inh, cells co-transfected with both pRL-SV40 and pGL3 vectors plus let-7a inhibitor; pRL-Muc1-let-7a inhi, cells co-transfected with both pRL-Muc1 and pGL3 vectors plus let-7a inhibitor; pRL-SV-let-7b inh, cells co-transfected with both pRL-SV40 and pGL3 vectors plus let$7 b$ inhibitor; pRL-Muc1-let-7b inhi, cells co-transfected with both pRL-Muc1 and pGL3 vectors plus let-7b inhibitor. Data are expressed as the mean \pm SEM from three replicates. Asterisks indicate statistical significance $(\mathrm{P}<0.05)$ by Student's $t$-test. (a)

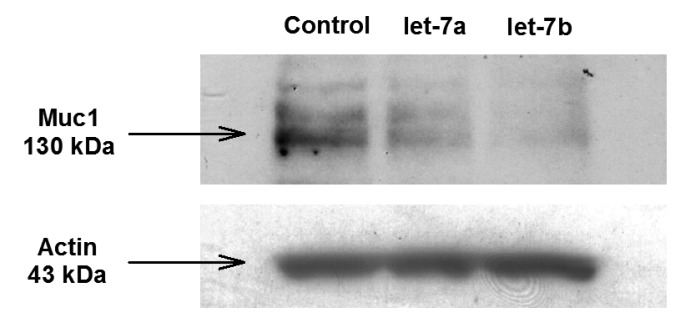

(b)

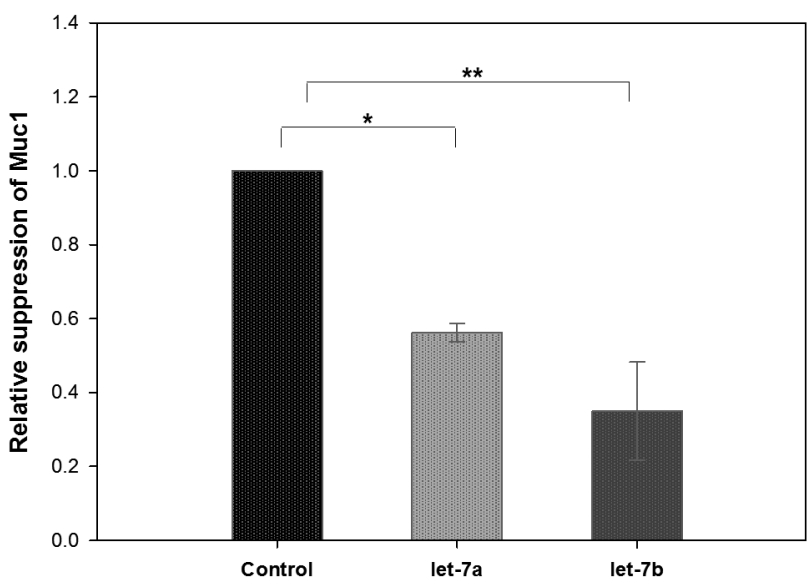

Fig. 4. Analysis of Western blotting revealed the reduction in Muc1 expression by the let-7a and let-7b precursors. Mouse epithelial cells isolated from four pregnant mice on day 1 in each of three replicate experiments $(\mathrm{n}=12$ mice) were seeded onto 6-well culture plates and transfected with/without $100 \mathrm{pmol}$ let-7a or let- $7 \mathrm{~b}$ precursor. The cells were analyzed $72 \mathrm{~h}$ after transfection by Western blotting (a). The relative expression of Muc1 was normalized to $\beta$-actin and analyzed with the ImageJ software (version 1.44p; National Institutes of Health, Bethesda, MD, USA); the cells transfected with Lipofectamine 2000 reagent only served as the control (b). Asterisks indicate statistical significance $(* \mathrm{P}<0.05 ; * * \mathrm{P}<0.01)$ by Student's $t$-test. Data are expressed as the mean \pm SEM.

Table 1. Evaluation of embryo adhesion ${ }^{\#}$ to the monolayer of uterine epithelial cells transfected with let-7a or let-7b precursors

\begin{tabular}{ccc}
\hline Treatment of epithelia* & Embryo no. & Attachment (\%) \\
\hline Control & 32 & $6 / 32(18.75 \pm 6.25)^{\mathrm{a}}$ \\
Let-7a & 32 & $11 / 32(34.38 \pm 10.67)^{\mathrm{a}}$ \\
Let-7b & 32 & $15 / 32(46.88 \pm 5.98)^{\mathrm{b}}$ \\
\hline
\end{tabular}

\# The hatching mouse embryos were cultured on the uterine epithelial cells for $24 \mathrm{~h}$, and embryo attachment was scored (4 replicates, total 12 mice used). * The uterine epithelial cells were collected from mice on day 1 of pregnancy ( 4 replicates, total 8 mice used) and transfected with let-7a or let-7b precursors for $48 \mathrm{~h}$ before being cultured with mouse blastocysts. Different superscripts in the same column indicate significant differences $(\mathrm{P}<0.01$, Chi-squared test). 
in oocyte maturation, early development, and embryo implantation [20,33]. miR-200a can downregulate phosphatase and tensin homolog (PTEN) levels, resulting in a reduction of pregnancy rates by affecting embryo implantation in mice [21]. Additionally, during embryonic development in mice, let-7 was previously found to be highly expressed in mature oocytes and zygotes; however, expression continuously decreased from the 2-cell to the 8-cell stage [33]. In contrast, let-7a expression in the uterus was significantly induced by active blastocysts, the process of embryo invasion, and decidualization during the implantation window, indicating the importance of let-7a in embryo implantation [18]. Based on results from microarrays, Northern blotting and in situ hybridization, let-7a and let-7b expression are significantly increased in the implantation sites compared with the inter-implantation sites in mouse uteri on day 5 of pregnancy $[4,24]$. Other data further indicated that let- $7 b$ gradually increased from day 1 to day 4 of pregnancy, with expression reaching the highest level on day 4 [3]. In the present study, the real-time RT-PCR results showed that let-7a increased from day 1 to day 4, with significantly higher expression on day 4 (Fig. 2), similar to the pattern observed with let- $7 b[3]$.

Because miRNAs require only partial matching to the target sequences [34-38], we applied computer-based sequence analyses to predict candidate targets of let-7a and let-7b. The results suggested that these two miRNAs might regulate Muc1 (Fig. 3a). Luciferase reporter assays are a commonly used method to ascertain the direct binding and regulation between miRNAs and their predicted target mRNAs $[39,40]$. Using a luciferase assay, we found that luciferase activity was significantly decreased after transfection with pRL-Muc1, while expression was restored by co-transfection with let-7a and let-7b inhibitors (Figs. $3 \mathrm{~b}$ and c). Therefore, we demonstrated that let-7a and let-7b can interact directly with the 3'UTR of Muc1. Next, we provided evidence from Western blotting showing that let-7 $a$ and let-7b can mediate Muc 1 expression. The results revealed that the expression of Muc1 was significantly decreased $72 \mathrm{~h}$ after transfection with let-7a and let-7b (Fig. 4). Additionally, our previous study demonstrated that Muc1 protein expression was regulated by miR-199a [25], indicating that Muc1 protein levels are not only regulated by $m i R-199 a$ but also by let-7a and let-7b. It is known that one miRNA can bind to and regulate more than 100 different mRNAs; furthermore, a single mRNA can be regulated by different miRNAs [41]. To our knowledge, this is the first study to reveal the expression patterns of Muc1 and let-7a/let-7b in mouse endometrial epithelia during implantation and to demonstrate the regulation of Muc1 by let-7a and let-7b.

Muc1 prevention of embryo attachment has been demonstrated by both in vitro embryo implantation and embryo-cell (an embryo with cells) aggregation assays [42]. Complete downregulation of Muc1 could increase the receptivity of the endometrial epithelium to embryo adhesion in vitro, although Mucl represents only $10 \%$ of the total cell-associated mucins in the mouse endometrial epithelia $[11,43,44]$. The function of the physiological reduction of Muc1 caused by let-7 $a$ and let-7 $b$ was validated by the in vitro embryo adhesion assay. Our results showed that mouse blastocysts exhibited significantly increased rates of attachment to endometrial epithelial cells transfected with let-7b mimics compared with the group in which the epithelia had not been transfected (Table 1). Therefore, we suggest that uterine receptivity resulting from the reduction of Muc1 could be regulated by let-7a and let- $7 b$.

In conclusion, in the present study, we clearly demonstrated the expression patterns of Muc1, let-7a and let-7b in mouse uterine epithelial cells during early pregnancy. Our findings identified Muc1 as a direct target of let-7a and let-7b. Due to the regulation of miRNA during the process of implantation, we propose that a better understanding of the physiological and molecular mechanisms responsible for implantation could help to improve modern reproductive therapies.

\section{Acknowledgments}

In addition to the partial financial support from the Ministry of Science and Technology (NSC 95-2313-B-005-035-MY2 and NSC 101-2313-B-005-006), this study was supported in part by a grant from the Ministry of Education, Taiwan, under the ATU (Aim for the Top University) plan.

\section{References}

1. Koot YEM, Teklenburg G, Salker MS, Brosens JJ, Macklon NS. Molecular aspects of implantation failure. Biochim Biophys Acta (BBA) - Molecular Basis of Disease 2012; 1822: 1943-1950. [Medline] [CrossRef]

2. Chae JI, Kim J, Lee SG, Jeon YJ, Kim DW, Soh Y, Seo KS, Lee HK, Choi NJ, Ryu J, Kang S, Cho SK, Lee DS, Chung HM, Koo AD. Proteomic analysis of pregnancyrelated proteins from pig uterus endometrium during pregnancy. Proteome Sci 2011; 9: 41. [Medline] [CrossRef]

3. Fu TY, Lin CT, Tang PC. Steroid hormone-regulated let-7b mediates cell proliferation and basigin expression in the mouse endometrium. $J$ Reprod Dev 2011; 57: 627-635. [Medline] [CrossRef]

4. Hu SJ, Ren G, Liu JL, Zhao ZA, Yu YS, Su RW, Ma XH, Ni H, Lei W, Yang ZM. MicroRNA expression and regulation in mouse uterus during embryo implantation. J Biol Chem 2008; 283: 23473-23484. [Medline] [CrossRef]

5. Brayman M, Thathiah A, Carson DD. MUC1: a multifunctional cell surface component of reproductive tissue epithelia. Reprod Biol Endocrinol 2004; 2: 4. [Medline] [CrossRef]

6. Gendler SJ. MUC1, the renaissance molecule. J Mammary Gland Biol Neoplasia 2001; 6: 339-353. [Medline] [CrossRef]

7. Thathiah A, Carson DD. Mucins and blastocyst attachment. Rev Endocr Metab Disord 2002; 3: 87-96. [Medline] [CrossRef]

8. Aplin JD, Meseguer M, Simón C, Ortíz ME, Croxatto H, Jones CJ. MUC1, glycans and the cell-surface barrier to embryo implantation. Biochem Soc Trans 2001; 29: 153-156. [Medline] [CrossRef]

9. Spencer TE, Johnson GA, Bazer FW, Burghardt RC. Implantation mechanisms: insights from the sheep. Reproduction 2004; 128: 657-668. [Medline] [CrossRef]

10. Meseguer M, Aplin JD, Caballero-Campo P, O'Connor JE, Martín JC, Remohí J, Pellicer A, Simón C. Human endometrial mucin MUC1 is up-regulated by progesterone and down-regulated in vitro by the human blastocyst. Biol Reprod 2001; 64: 590-601. [Medline] [CrossRef]

11. Bowen JA, Bazer FW, Burghardt RC. Spatial and temporal analyses of integrin and Muc-1 expression in porcine uterine epithelium and trophectoderm in vivo. Biol Reprod 1996; 55: 1098-1106. [Medline] [CrossRef]

12. DeSouza MM, Mani SK, Julian J, Carson DD. Reduction of mucin-1 expression during the receptive phase in the rat uterus. Biol Reprod 1998; 58: 1503-1507. [Medline] [CrossRef]

13. Hild-Petito S, Fazleabas AT, Julian J, Carson DD. Mucin (Muc-1) expression is differentially regulated in uterine luminal and glandular epithelia of the baboon (Papio anubis) Biol Reprod 1996; 54: 939-947. [Medline] [CrossRef]

14. Surveyor GA, Gendler SJ, Pemberton L, Das SK, Chakraborty I, Julian J, Pimental RA, Wegner CC, Dey SK, Carson DD. Expression and steroid hormonal control of Muc1 in the mouse uterus. Endocrinology 1995; 136: 3639-3647. [Medline]

15. Lee KY, DeMayo FJ. Animal models of implantation. Reproduction 2004; 128: 679-695 [Medline] [CrossRef]

16. Horne AW, Lalani EN, Margara RA, White JO. The effects of sex steroid hormones and interleukin-1-beta on MUC1 expression in endometrial epithelial cell lines. Reproduction 2006; 131: 733-742. [Medline] [CrossRef]

17. Xia HF, Jin XH, Song PP, Cui Y, Liu CM, Ma X. Temporal and spatial regulation of 
miR-320 in the uterus during embryo implantation in the rat. Int J Mol Sci 2010; 11: 719-730. [Medline] [CrossRef]

18. Xia HF, Jin XH, Song PP, Cui Y, Liu CM, Ma X. Temporal and spatial regulation of let-7a in the uterus during embryo implantation in the rat. J Reprod Dev 2010; 56: 73-78. [Medline] [CrossRef]

19. Xia HF, Jin XH, Cao ZF, Shi T, Ma X. MiR-98 is involved in rat embryo implantation by targeting Bcl-xl. FEBS Lett 2014; 588: 574-583. [Medline] [CrossRef]

20. Geng Y, He J, Ding Y, Chen X, Zhou Y, Liu S, Liu X, Wang Y. The differential expression of microRNAs between implantation sites and interimplantation sites in early pregnancy in mice and their potential functions. Reprod Sci 2014; 21: 1296-1306. [Medline] [CrossRef]

21. Shen LJ, He JL, Yang DH, Ding YB, Chen XM, Geng YQ, Liu SJ, Liu XQ, Wang YX. Mmu-microRNA-200a overexpression leads to implantation defect by targeting phosphatase and tensin homolog in mouse uterus. Reprod Sci 2013; 20: 1518-1528. [Medline] [CrossRef]

22. Liu X, Gao R, Chen X, Zhang H, Zheng A, Yang D, Ding Y, Wang Y, He J. Possible roles of mmu-miR-141 in the endometrium of mice in early pregnancy following embryo implantation. PLoS ONE 2013; 8: e67382. [Medline] [CrossRef]

23. Xia HF, Cao JL, Jin XH, Ma X. MiR199a is implicated in embryo implantation by regulating Grb10 in rat. Reproduction 2014; 147: 91-99. [Medline] [CrossRef]

24. Chakrabarty A, Tranguch S, Daikoku T, Jensen K, Furneaux H, Dey SK. MicroRNA regulation of cyclooxygenase-2 during embryo implantation. Proc Natl Acad Sci USA 2007; 104: 15144-15149. [Medline] [CrossRef]

25. Inyawilert W, Fu TY, Lin CT, Tang PC. MicroRNA-199a mediates mucin 1 expression in mouse uterus during implantation. Reprod Fertil Dev 2014; 26: 653-664. [Medline] [CrossRef]

26. Fu TY, Chang CC, Lin CT, Lai CH, Peng SY, Ko YJ, Tang PC. Let-7b-mediated suppression of basigin expression and metastasis in mouse melanoma cells. Exp Cell Res 2011; 317: 445-451. [Medline] [CrossRef]

27. Braga VM, Gendler SJ. Modulation of Muc-1 mucin expression in the mouse uterus during the estrus cycle, early pregnancy and placentation. J Cell Sci 1993; 105: 397-405. [Medline]

28. Dharmaraj N, Wang P, Carson DD. Cytokine and progesterone receptor interplay in the regulation of MUC1 gene expression. Mol Endocrinol 2010; 24: 2253-2266. [Medline] [CrossRef]

29. Hollingsworth MA, Swanson BJ. Mucins in cancer: protection and control of the cell surface. Nat Rev Cancer 2004; 4: 45-60. [Medline] [CrossRef]

30. Song Y, Wang Q, Huang W, Xiao L, Shen $\mathbf{L}, \mathbf{X u}$ W. NF $\kappa B$ expression increases and CFTR and MUC1 expression decreases in the endometrium of infertile patients with hydrosalpinx: a comparative study. Reprod Biol Endocrinol 2012; 10: 86. [Medline]
[CrossRef]

31. Paria BC, Reese J, Das SK, Dey SK. Deciphering the cross-talk of implantation: advances and challenges. Science 2002; 296: 2185-2188. [Medline] [CrossRef]

32. Ma WG, Song H, Das SK, Paria BC, Dey SK. Estrogen is a critical determinant that specifies the duration of the window of uterine receptivity for implantation. Proc Natl Acad Sci USA 2003; 100: 2963-2968. [Medline] [CrossRef]

33. Tang F, Kaneda M, O'Carroll D, Hajkova P, Barton SC, Sun YA, Lee C, Tarakhovsky A, Lao K, Surani MA. Maternal microRNAs are essential for mouse zygotic development. Genes Dev 2007; 21: 644-648. [Medline] [CrossRef]

34. Guo Y, Ying L, Tian Y, Yang P, Zhu Y, Wang Z, Qiu F, Lin J. miR-144 downregulation increases bladder cancer cell proliferation by targeting EZH2 and regulating Wnt signaling. FEBS J 2013; 280: 4531-4538. [Medline] [CrossRef]

35. Chan HW, Lappas M, Yee SW, Vaswani K, Mitchell MD, Rice GE. The expression of the let-7 miRNAs and Lin28 signalling pathway in human term gestational tissues. Placenta 2013; 34: 443-448. [Medline] [CrossRef]

36. Felli N, Fontana L, Pelosi E, Botta R, Bonci D, Facchiano F, Liuzzi F, Lulli V, Morsill O, Santoro S, Valtieri M, Calin GA, Liu CG, Sorrentino A, Croce CM, Peschle C. MicroRNAs 221 and 222 inhibit normal erythropoiesis and erythroleukemic cell growth via kit receptor down-modulation. Proc Natl Acad Sci USA 2005; 102: 18081-18086. [Medline] [CrossRef]

37. Bartel DP. MicroRNAs: genomics, biogenesis, mechanism, and function. Cell 2004; 116: 281-297. [Medline] [CrossRef]

38. Garzon R, Calin GA, Croce CM. MicroRNAs in Cancer. Annu Rev Med 2009; 60: 167-179. [Medline] [CrossRef]

39. Zhao C, Sun G, Li S, Lang MF, Yang S, Li W, Shi Y. MicroRNA let-7b regulates neura stem cell proliferation and differentiation by targeting nuclear receptor TLX signaling. Proc Natl Acad Sci USA 2010; 107: 1876-1881. [Medline] [CrossRef]

40. Li R, He J, Chen X, Ding Y, Wang Y, Long C, Shen L, Liu X. Mmu-miR-193 is involved in embryo implantation in mouse uterus by regulating GRB7 gene expression. Reprod Sci 2014; 21: 733-742. [Medline] [CrossRef]

41. Kim VN. MicroRNA biogenesis: coordinated cropping and dicing. Nat Rev Mol Cell Biol 2005; 6: 376-385. [Medline] [CrossRef]

42. Devine PL, McKenzie IF. Mucins: structure, function, and associations with malignancy. BioEssays 1992; 14: 619-625. [Medline] [CrossRef]

43. Pimental RA, Julian J, Gendler SJ, Carson DD. Synthesis and intracellular trafficking of Muc-1 and mucins by polarized mouse uterine epithelial cells. J Biol Chem 1996; 271 28128-28137. [Medline] [CrossRef]

44. DeSouza MM, Surveyor GA, Price RE, Julian J, Kardon R, Zhou X, Gendler S, Hilkens J, Carson DD. MUC1/episialin: a critical barrier in the female reproductive tract. J Reprod Immunol 1999; 45: 127-158. [Medline] [CrossRef] 